\title{
Consumer preferences for development of home textiles inspired from geometrical mosaic tile motifs
}

\author{
Jaskiran Kaur and Vandana Gandotra
}

Received: 26.04.2019; Revised: 26.10.2019; Accepted: 10.11.2019

See end of the paper for authors' affiliations

\section{Jaskiran Kaur}

Department of Apparel and

Textile Science, College of

Home Science, Punjab

Agricultural University,

Ludhiana (Punjab) India

Email : jaskirank4@gmail.com
ABSTRACT : The present study was undertaken for design development of home textiles using geometrical mosaic tile motifs. For conducting the study preferences were taken from sixty women from different areas in Ludhiana city. An interview schedule was prepared for collecting data from sixty respondents regarding the preferences for fabrics, embellishments etc. The results of the investigation were interpreted using weighted mean scores. The results of the collected data revealed that most preferred fabric type was cotton. Twenty designs were developed according to the preferences of respondents in Corel Draw X3.

KEY WORDS: Mosaic, Home textiles, Screen printing, Coral Draw X3

- HOW TO CITE THIS PAPER : Kaur, Jaskiran and Gandotra, Vandana (2019). Consumer preferences for development of home textiles inspired from geometrical mosaic tile motifs. Asian J. Home Sci., 14 (2) : 385-389, DOI: 10.15740/HAS/AJHS/14.2/385-389. Copyright@ 2019: Hind Agri-Horticultural Society. 